BANTU IN THE CRYSTAL BALL, II*

Jan Vansina

University of Wisconsin

Interest in the question of Bantu expansion rose dramatically in the 1950 s as historians, archeologists, and anthropologists all joined in the fray. This reflected both the rise of Africa in world affairs and the expansion of research in general. The scholars involved were typically a new breed of professionals, and as such more dependent than their predecessors on universities or research institutions. The School of Oriental and African Studies in London achieved overwhelming dominance from about 1950 until the late 1960s, so that opinions held by its staff found the widest audience. The new scholars also were, for the most part, anti-racist, sympathetic to African nationalisms, and of liberal or socialist persuasion. They tended to reject the notion of "conquest," believing in gradual change rather than abrupt cataclysmic mutation, perhaps because they were repelled by their recent experiences during the war. As had happened earlier, these extraneous circumstances left a deep imprint on the speculations that were now proposed. ${ }^{154}$ Early in this period a new paradigm almost achieved consensus, but after 1968 this fell apart and during the last decade two new trends have appeared: the single-minded quest for a new paradigm and the search for better understanding through the study of analogous processes, coupled with a more radical skepticism.

\title{
Murdock
}

H.H. Johnston's views still held the field in the early 1950s. Remember that he held that the Bantu spread as a result of a massive migration and conquest which began perhaps two millennia ago in the interlacustrine area. An occasional variant -- such as that proposed by Schebesta, who held that both Bantu and "Sudanic" languages had evolved from the primordial language of the pygmies in Ituri -- attracted no following. ${ }^{55}$ Joseph Greenberg's new classification of African languages, however, was slowly gaining acceptance, especially in the United States, where George P. Murdock, a culture historian of the school of Franz Boas, published a new hypothesis in 1959. For Murdock, the link between language and culture was much more significant than Herskovits had believed. Murdock argued that "in the absence, 
of written records, linguistic relationships provide by far the most dependable evidence of historical connection."156 Like Greenberg, Murdock's concern was with the continent as a whole and Bantu expansion was only one part of the fresco he wished to paint.

Murdock's anthropology was comparative, but rested on a passion for ethnography, so that his book is replete with potted ethnographic vignettes. A newcomer to African studies, he saw Africa through the eyes of someone who had long worked with North American Indian and Pacific materials. All this is reflected in his hypothesis that the Bantu expansion had been an "explosive expansion," though not a conquest, even though he did compare it to that of the Arabs after Muhammad, the Chinese occupation of southern China, and European expansion since the fifteenth century. The proto-Bantu homeland lay in Cameroun. The movement from there began about the first century A.D. and the Bantu speakers spread in "waves" into the forest, the occupation of which was made possible by the acquisition of new crops -the banana, taro, and yams, all originally from Malaysia. These had reached Cameroun via East Africa and then by a route north of the forest. Their cultivation led to a population explosion in the proto-Bantu area, which in turn induced the expansion and penetration of the forest, where the pygmies were easily reduced to a symbiotic dependence. ${ }^{157}$ People from the lowland portion of the Bantu domain moved along the coast to southern Gabon and as far as the Malebo Pool. 158 Another wave spread eastwards through the forest, emerging in Uganda. ${ }^{159}$

While the northern stream of Bantu became patrilineal under the influence of their northern "Nigritic" neighbors, the southern stream remained matrilineal as the proto-Bantu had been. ${ }^{160}$ In the interlacustrine area the Bantu expansion succeeded only by borrowing most of the culture of the older Cushitic inhabitants found there, including highly-complex state systems and cereal crops. They transmitted the new composite culture southward as far as the Cape. ${ }^{161}$ Tanzania was occupied by Bantu speakers from central Africa, who fanned out northward from Mozambique, where they met "Azanians" and occupied land disdained by the latter, expanding in this fashion as far north as the Banadir coast. 162 The southwestern Bantu came directly from the adjacent Bantu speakers in the woodlands, while expansion in southern Mozambique and $\mathrm{Zimbabwe}$ derived from other Bantu speakers in the woodlands to their north. 163 The last wave of expansion occurred in "the historical period" and carried Bantu speakers to Botswana after about 1720.164

Murdock's hypothesis was accompanied by precise dates, named spaces, and tangible and identiflable changes, and he provided explanations for all the whys and wherefores. Despite his protestation about the importance of linguistic evidence, his arguments used only the linguistic notion of a Cameroun cradleland; otherwise it derived from ethnographic data and culture change, which he implicitly saw mostly as a process of borrowing and adapting. He used "survivals" in a way typical of the culture historical school. Often he combined traces of survivals with survivals of complete systems. For instance, in 
his reconstruction of the original kinship system of the protoBantu as matrilineal and avunculocal, he stressed the "survival" value of the Nigerian plateau cultures. 165 In this fashion Murdock attempted to account for all the cultural diversities in the Bantu-speaking world. It was a grand vision, one which Hartland had perceived in inchoate form. But it was a mirage only. Too many hypothetical ghosts like the "Azanians" and "Megalithic Cushites" peopled the stage. Murdock's attempt, bold as it was, definitely was premature, so much so that no one since has even attempted to replace it by another hypothesis as complete. And no wonder: it involves the reconstruction of at least three thousand years of history over more than a third of a continent:

\section{The Iron Age of Bantu Studies}

Archeologists had long been active on the continent in search of the "missing link" and of the oldest stone age cultures, but had steadfastly ignored later sites. Desmond Clark was the first among them to take such sites in Bantu-speaking Africa other than Zimbabwe seriously. Clark was concerned about the relations between sites and present-day populations. ${ }^{166}$ His first survey, The Prehistory of Southerm Africa published in 1959, reflected the then-standard views about Bantu expansion, but he modified them in light of the results of fieldwork in southern Africa. Notably he insisted that Bantu was a linguistic term, not a race, and that Bantu speakers had migrated from east Africa, one of the basic strains being perhaps Mascudi's "Zenj."167 Clark argued that Bantu speakers were the first metal-using food producers in southern Africa, arriving first in small numbers as stock owners cum farmers and metallurgists. ${ }^{168}$ Later, new migrants came from the "Congo basin" -- "barbaric warriors" and agriculturalists who exterminated the earlier occupants. 169 This was the migration responsible for the great ruins of Rhodesia and Angola, he claimed, and added that "their culture shows connexions with the Congo and perhaps with southern Abyssinia, where it has been suggested that the Jagas may have originated."170 In summing up Clark equated the earlier Bantu speakers with the "channeled ware" people who were in Zambia C. A.D. 90 and also with the "stamped ware" people of Rhodesia C. A.D. 500. The "barbaric warrfors" arrived before $1400 \mathrm{~A} . \mathrm{D}$. and were associated with the "ruin ware." They ousted the "stamped ware" people, who retreated across the Limpopo. 171

Meanwhile, research in the Early Iron Age was also beginning in Uganda, Rwanda, and Shaba. The earliest known iron age in east Africa was dubbed "dimple based ware." Jean Hiernaux and Merrick Posnansky both concluded from its similarity with "channeled ware" further south that the so-called "dimple based ware" could represent physical traces of the Bantu expansion. Hiernaux first presented this view in a paper in 1959, but Posnansky was the first to pursue the matter seriously. 172 Influenced by Murdock, he discussed the evidence for the banana as a key to the Bantu expansion but argued instead that the agricultural revolution in general led to the build-up of population 
in Cameroun. But the establishment of iron metallurgy was the trigger for the expansion itself, especially since the Malaysian crops reached the proto-Bantu at about the same time that they learned how to smlt iron, so that they were able to use their new iron tools to clear land for their new crops. ${ }^{173}$ For Posnansky, bananas did not follow the route favored by Murdock, although their impact was the same.

The speculations of Clark, Hiernaux, and Posnansky were to exert a durable influence. The spread of languages was now equated both with the spread of a particular type of pottery and of iron technology. This association meant that archeologists of the Early Iron Age were all to be involved in the quest; it also implied that the Bantu expansion could be dated, since the relics of its baggage could be identified and dated. This premise was not to be questioned until well into the 1970 s.

The idea that Bantu speakers introduced iron had been held by Johnston. Basil Davidson's influential OZd Africa Rediscovered had also attributed "the progressive spread and multiplication of negroid peoples across the southern continent" to the onset of the iron age. 174 Davidson linked iron with 'divine kingship,' farming, "tribal collectivism," and building in stone, so that his interpretation had a strong deterministic ring to it.

The first historian to speculate in print about Bantu expansion was Christopher Wrigley, who initiated a long series of articles on the Bantu problem in the Jourmal of Africon History. Wrigley was strongly influenced by Murdock and Clark and knew Davidson's work. He reviewed the data about agriculture and concluded that, although Murdock had erred in ascribing the invention of cereal agriculture to Africans, they had innovated as a result of stimulus diffusion from the Middle East and had developed their own varieties of root crops. "It is conceivable," he added, "that in this limited sense the agriculture of Africa is original and that of the Middle East derivative."175 Here we find the imprint both of the exhilarating effects which movements of African nationalism had created and of the then-standard school of archeology, whose main exponent, Gordon Childe, held that all innovations ultimately derived from the Middle East.

For Wrigley the acquisition of iron was a necessary condition for the Bantu expansion. He saw the first Bantu speakers as a prestigious minority, valued because their iron spears provided the autochthones as well as themselves with larger quantities of meat. A later wave, however, was much more warlike. Their success, he thought along with Clark, was based on military organization and on warrior ethos, which arose from the full exploitation of the iron spear. ${ }^{176}$ In passing, Wrigley chided Davidson for equating the history of Africa with the history of the Iron Age, but then fell into the same trap by explaining that the iron spear was responsible for the disintegration as well as the creation of the Bantu states of the second wave, because the rulers could not control the manufacture and distribution of spears. Wrigley then argued for the ambivalence of iron technology, which led both to swords and ploughshares. This thesis was close to those of Davidson, Posnansky, Hiernaux, and Clark, except for a 
new shadow. Wrigley referred to research in England which saw the cradle of Bantu not in Cameroun but "towards the south-centre of their present sphere."177 The shadow was Malcolm Guthrie, whose views were beginning to challenge the Greenberg hypothesis.

\section{The London Paradigm}

In the 1950s SOAS achieved an extraordinary standing in African studies, especially in African history. The school furnished the external examiners for all the English-speaking colleges in east and central Africa. In history there was only one specialist, Roland Oliver, and he took a leading role. He was a founding father of the modern historiography of Africa, and organized the conferences on the History and Archaeology of Africa in 1953, 1957, and 1961. Oliver firmly believed in interdisciplinary research, especially, but not only, between historians and archeologists. He also was a dynamic promoter of the field and became the hub of a communication web which included not only his colleagues in other disciplines at SOAS but also the staff at Makerere College in Uganda, historians at other colleges in east and central Africa, and personalities such as Davidson, Clark, Posnansky, and, later, Fagan. In 1960 he co-founded the Joumal of African History with John Fage and has created many opportunities for publication and research in the field ever since.

Oliver, who had written a political biography of Johnston, accepted Johnston's views as late as 1958, although he rejected his stress on conquest and proposed a dating for the beginning of the expansion that pushed it back to around $3000 \mathrm{~B}$.C. because his colleague at SOAS, Malcolm Guthrie, had convinced him that domestic fowl were a late introduction into the Bantu-speaking world and could not be used as an argument for dating. ${ }^{78}$ Guthrie, who did not attend the conference on history and archaeology of Africa at SOAS in 1957, began in 1958 to assess the historical implications of his comparative work, encouraged by oliver. By the following January, he was ready to state his main views. These were that Greenberg was completely wrong, the cradle of the Bantu languages lay in the center and from there Bantuisms were ultimately carried to west Africa. 179

Oliver had accepted Guthrie's views by February 1959, but still refused to abandon Greenberg's schema, which he thought was bolstered by the Nok dates. Guthrie suggested that probably the "carriers of iron" came to the Bantu cradleland by canoe through the forest or, less likely, around it. For iron metallurgy had reached the Bantu cradle before they dispersed. At least that was what Guthrie then called a "reasonable hypothesis." By the end of that seminar session a synthesis had begun to take shape, in which the coming of iron to the early Bantu south of the forest triggered their expansion. ${ }^{180}$ At a later session the seminar admitted that there were "a large number of imponderables which make the use of linguistic analysis for recent history rather difficult" but did not draw the further conclusion that perhaps similar imponderables for more remote times would make such use of linguistic data even more difficult. ${ }^{81}$ 
Attendance at these sessions of the African History Seminar included archeologists as well as historians, a musicologist, and a culture history-minded anthropologist, G.W.B. Huntingford. From the minutes it is evident that Oliver, the organizer, was attempting to achieve a synthesis on the basis of all these disciplines and was not ready to drop Greenberg's theory completely. He was not just blindly following Guthrie's assurances on this point. Perhaps his attitude on this was not conditioned so much by a close examination of the evidence as by the assurance of another linguist at SOAS, Archibald N. Tucker, that Greenberg was not to be dismissed out of hand. If so, Oliver's approach to interdisciplinary research was to doubt only when there was no unanimity among specialists of a single discipline.

The impact of these sessions of the seminar was visible in Wrigley's article, as well as in a later publication by Huntingford, who saw Bantu speakers moving from the Congo during the early centuries A.D. These were matrilineal and forged iron. Physically they were a mixture of Hamite and Negro, while culturally they belonged to two ethnotypes: one from west or northwest of Lake Victoria and the other from the Congo. The first was a Bantu culture modified by Hamitic influences, while the second was a "pristine" Bantu culture. 182 The theme of a Bantu culture wedded to Bantu languages, albeit common enough in popular usage, was not to appear in the literature again until well into the 1970 s. Huntingford's views still exhibited strong influences from Johnston and the German culture historical school, but indirectly also from Greenberg, Guthrie, and recent Iron Age archeology. In retrospect it is evident that the potpourri of data would not yet yield a plausible paradigm.

In 1962 0liver's first at tempt at synthesis appeared in his and Fage's A Short History of Africa. ${ }^{183}$ This showed traces of all these influences and of Murdock's stress on overpopulation and agriculture as well. His view was that overpopulation in the savanna near Lake Chad during the last three millennia B.C. led to emigration. The proto-Bantu were a group of Iron Age hunters and fishermen who crossed the forest using waterways and then, on the southern margins of the forest, adopted the cultivated plants of the Malaysian complex. Around the beginning of the Christian era they began to expand from a nuclear area south of the forest and absorbed the autochthonous populations. This was a difficult undertaking in east and southern Africa, where they met "Hamites." Any straight forward association of the Bantu expansion with the "dimple based" or "channeled ware" potteries was to be excluded.

In the same year Guthrie published three articles. ${ }^{184}$ His article in the Joumal of African History made clear that the Bantu speakers were iron users and graphically represented their dispersal from an area linking Kongo via Luba to Swahili.185 This was mapped in the Joumal of African Languages as an area stretching from coast to coast and from the north end of Lake Tanganyika to the lower Kafue. 186 He also stated as a "provisional hypothesis" that the nucleus of proto-Bantu had been midway on this line, that is, in Shaba. Johnston and Greenberg were conjured up only to be dismissed because their centers of 
origin ignored what Guthrie saw as problems of terrain and vegetation during the migrations. In this regard Guthrie spoke of "an impenetrable forest" and argued on the basis of his own experience that "the progenitors" of the Bantu speakers could not have crossed it. Proto-Bantu could be descended from a preBantu spoken somewhere near Lake Chad and propagated by "skilled canoemen." Some of these groups went to west Africa, which explained Bantuisms in languages there, while others crossed the equatorial forest barrier by shooting down the waterways of the Congo basin. The original proto-Bantu may or may not have had iron metallurgy. If not, the skill reached them from their descendants who had remained in the Chad area or from collaterals of such descendants. Whenever and however acquired, the art of ironworking allowed expansion to begin and proceed apace. 187

Despite some obvious weaknesses (such as descendants keeping track of each other across an "impenetrable" equatorial forest), Guthrie's publications had immediate influence in France, where the foremost publicists in the field, Hubert Deschamps and Robert Cornevin,introduced his ideas in modified form. Deschamps saw a link between the crossing of the forest and the desiccation of the Sahara.188 Cornevin on the other hand linked the cradle to the known sites at Sanga in Shaba. For him most of the protoBantu never crossed the forest but moved east along its edge, while the rest crossed it via the Sangha or Ubangi and emerged near Kinshasa to form the western Bantu nucleus. The main force rounded the forest along the great lakes and eventually reached Shaba, where they became the eastern Bantu nucleus. ${ }^{189} \mathrm{He}$ therefore accepted Guthrie but put the separation between eastern and western Bantu before departure in the northwest rather than in Shaba.

But these early efforts were not satisfying. Most scholars could not reconcile the archeological data concerning Early Iron Age Africa with these theories, nor did they know how to choose between Greenberg and Guthrie or to blend their claims. ${ }^{190}$ The SOAS paradigm was not yet sufficiently crystallized and outside of the school many remained perplexed. Archeologists kept insisting that the dimple based/channeled ware cultures represented the Early Iron Age population.

The mature version of the paradigm was articulated by Oliver in 1965, published the following year, and immediately gained wide acceptance, even outside SOAS circles.191 In this version Bantu expansion meant "the substantial repopulation of half a continent" for, oliver argued, it was no conquering migration, but the product of population growth, a colonization. oliver did not invoke a germ carried by the new settlers, harmless to them but deadly to the previous population, as Johnston once did, but saw the Bantu speakers coming in such numbers that they swamped and assimilated the aborigines. The western Sudan had become thickly populated as a result of the food-producing resolution (and here he recognized Clark), but this expansion was halted at the edges of the forest. In this sense Greenberg's cradle was correct. But so was Guthrie's proposition, since the early Bantu moved from Cameroun to Shaba along the Sanga and 
Ubangi rivers, having perfected their boatbuilding skills thanks to iron working skills already learned in Nigeria.

This constituted Oliver's stage I. Stage II was the expansion of the population in Shaba from coast to coast and the borrowing of cereals cultivated by Cushites in eastern Africa. The first reference to Bantu speakers on the coast may well have been by Ptolemy in the first century A.D. On the east coast Bantu speakers acquired the Malaysian crops and this set the scene for stage III, during which vastly increased Bantu populations moved into wetter areas, especially toward the interlacustrine regions, Zambia, and all along the humid East coast. That happened between 500 and 1000 A.D. Stage IV saw the colonization of the remainder of the equatorial forest, southeast Africa, and the interior of eastern Africa.

Oliver held that the Early Iron Age in eastern Africa was not solely a Bantu-related phenomenon, though he argued that the Later Iron Age was. His distinction between two iron ages followed Clark and Wrigley. The difficulty lay in explaining the Early Iron Age. This was, Oliver felt, introduced by Bantu speakers, but the techniques spread ahead of their expansion into southeastern Africa, as evidenced by the Khoi or San skeletons at Mapungubwe. Those sites should be contrasted with Sanga and the Kalambo site in Zamb1a, which, he argued, were linked to the first Bantu population build-up. This meant that the "channeled ware" tradition was Bantu; this did not spread, however, from north to south as archeologists believed, but from south to north, and its spread belonged to stage III. State building in the interlacustrine area occurred as a reaction to Nilotic pressure and it may have owed much to influences from conquering minorities from Ethiopia and Sudan.

0liver's article was a masterful synthesis of existing points of view insofar as it reconciled the positions of all major views since 1949 and was susceptible to checking by further archeological work. Soon after its publication articles by both Posnansky and Hiernaux endorsed the schema. Posnansky stressed the difference between channeled ware and dimple based ware and suggested that both derived from an unknown single source $X$, which was to be sought somewhere west of east Africa (perhaps in Shaba!). He felt, though, that oliver had underestimated the west African origins of the Bantu expansion.192 Hiernaux, a physical anthropologist, concluded his major revision of human biology by 1968.193 In an article in Joumal of Africon History he claimed that linguistics, archeology, and human biology all yielded results which supported O1iver's thesis. ${ }^{194}$ The paradigm seemed to have triumphed. It appeared as if its now silenced opponents were merely lagging behind the times.

\section{The Decline and Fall of the London Paradigm}

Yet when Oliver and Brian Fagan, an Iron Age specialist in archeology and a close collaborator of Oliver since 1960, called a conference on the Bantu expansion at Chicago in 1968, the meetings did not just tie up loose ends in the paradigm. Serious 
disagreements soon surfaced. Some historians and linguists realized that many Bantuists did not accept Guthrie's theories, but were waiting for the full results of his work to be published before they voiced any criticism. Most influential among these critics were Greenberg and Albert E. Meeussen. ${ }^{195}$ All the participants at the Chicago meeting accepted Greenberg's views and much of the discussion was devoted to whether the first Bantu speakers skirted the forest to reach central Africa or whether they crossed it. Those who favored the second possibility wanted to eliminate Guthrie's cradle altogether. Posnansky's idea about the relationship between "dimple based" ware and "channeled ware" ware found favor and was expanded with the help of the concept of "co-tradition" developed by American archeologists. But there were more than just two types of pottery involved. Thomas Huffman argued that, although archeologists fell into camps of "lumpers" and "splitters" on this score, they nevertheless all accepted a common "culture" as the fons et origo of all these members of the co-tradition. He believed, and no one contradicted him, that this ancestral culture could be found in Zaire or Angola, with Mozambique as a less likely alternative. In other words, culture $X$ (not yet found) was located in place $Y$ (where no excavations had as yet been undertaken).

Some attention was also given to the linguistic indications in proto-Bantu concerning the use of iron. As the first volume of Guthrie's Comparative Bantu had just appeared it could be ascertained that the evidence was equivocal. Thus the item "to forge" might also mean "to hammer;" the item for "iron ore" could also mean "stone;" "iron" could also mean "valuables;" etc. As a result it could be argued that originally all these roots referred to the technology of a Stone Age people. As to the real links between languages and biological characteristics of populations, it soon became clear that the osteological remains were far too scarce to allow any firm conclusions. Whatever conclusions were reached, it was highly unlikely that they could throw light on languages spoken.

Some of these concerns found their way only into the Conference Report but some of the participants, dissenters or not, prepared their own publications. 196 Huffman elaborated his views when he held that the original co-tradition probably evolved in Shaba and could represent either the proto-Bantu stage or the proto-eastern Bantu expansion only. 197 This ancestral culture split into two groups, an eastern and a southern African group, and each later divided into a number of variants as attested by the archeological record. Desmond Clark proposed that the earliest Bantu speakers, who crossed the forest as in the London paradigm, lost their cereal agriculture on the way and did not know how to smelt iron. 198 They acquired both techniques south of the forest and separated, still according to the paradigm, into western and eastern streams. The western Bantu then must have left the cradle before $200 \mathrm{~A} . \mathrm{D}$. and the eastern stream is represented by the "dimple based" and "channeled ware" sites. His article, however, is perhaps most remarkable in that, by considering various sorts of alternatives, he unintentionally demonstrated 
how easily archeological evidence can be tailored to fit any linguistic theory that might be advanced. It all depends on which cultures one chooses to equate with which group of people.

Christopher Ehret and I had attended the Chicago conference and were also dissatisfied, although we both believed that some kind of paradigm could still be set up. I used the Horizon History of Africa to propose a different scenario, taking Clark's attribution of the expansion to population increase, but locating it in Cameroun, rejecting Guthrie's arguments completely.19g Arguing that life in the forest was more pleasant than in the savanna, especially along the numerous ecological boundaries, I suggested that it was reasonable that the Bantu expanded southwards without compulsion. This movement was neither a compact migration nor a colonization, although I reflexively used terms like "migration" and "wave." The Bantu speakers carried their cereals through the forest but their progress halted for a while at the forest's edge in order to adapt their technology to new environments. The expansion then followed major rivers south of the forest, being always mindful of favorable environments. The Bantu speakers finally reached the east coast in the lower Zambezi area and then spread north and south. Meanwhile, other groups followed the forest's edge to the east until they emerged in the interlacustrine area, where there was already a sizeable population, so that the expansion made much slower headway there. By the time Bantu speech reached Lake Victoria it had reached Zanzibar from the south.

The relation with iron-working was complex. The proto-Bantu had not been iron users. The interlacustrine Bantu learned the art from the autochthones and the northwest Bantu speakers acquired it from Nigeria, while on the east coast Arab traders brought the technology. The eastern Bantu speakers also acquired cattle from the previous inhabitants. The last phase of the expansion occurred between the first and fifth centuries A.D., with Bantu speakers crossing the Zambezi and progressing slowly in Kenya and Tanzania. The dating was unclear but earlier, on the whole, than in the SOAS paradigm so that Bantuization was seen as a lengthy process. Language shifts were caused by social conditions. Bantu speakers lived in compact settlements and imposed their speech on the dispersed populations around them but, as the differences between "town" and "country" were slight, the process was a gradual one. I also drew attention to the massive evidence for convergence in borrowing, which made it possible to evolve a genetic classification of Bantu languages. 200

Ehret had already demonstrated in 1967 that cattle spread into southern Africa from east Africa and this impugned one of the reconstructions of Guthrie. ${ }^{201}$ Now he attacked Guthrie's views directly in a relatively obscure article. 202 Ehret was the first to stress the importance of core vocabulary as evidence, argued that northwest Bantu and all the rest were equal branches of proto-Bantu, and found in this a strong confirmation for Greenberg's views on the spread of Bantu languages. The Bantu first spread into the forest and only later outward from it. The later spread of eastern bantu languages occurred about 2000 
years ago and was to be correlated with the east African Early Iron Age. The beginning of the earlier expansion should be dated to before 1000 B.C., that is, before agriculture had spread to the proto-Bantu. Ehret also stressed the importance of borrowing, an aspect of historical linguistics which was his special area of research.

Greenberg, who had not attended the Chicago meeting, reasserted his own views, rejecting Oliver's compromise and rebutting Guthrie with great care. ${ }^{203}$ It was an admirable rebuttal, but one that probably was too technicial for the average reader.

In any case, the London paradigm continued to be accepted by most English-speaking scholars who, at the time, still represented the great majority of Africanists. It became the basic paradigm for further enquiry by physical anthropologists, archeologists, and historians. It also began to appear in textbooks. Whereas Robert Rotberg in 1966 had simply listed Greenberg and Guthrie's views side by side, basing himself on literature up to 1962, Robert Collins used Oliver's article as the capstone in a section where Bantu expansion was presented as a "problem" for students, and Harry Gailey's text called the same piece "a perceptive composite analysis." 204 If textbooks are always behind the times, they nevertheless consecrate an earlier consensus. In France Pierre Alexandre's contribution to Histoire générale de l'Afrique noire cited both Greenberg and Guthrie, but then claimed without further elaboration that the Cameroun data agreed with Guthrie's views. 205

In time the London paradigm was accepted by many in France. Randles used it, although he held that the proto-Bantu arrived in Shaba after having skirted the entire forest, rather than crossing it. He duly identified the Eariy Iron Age cultures of eastern and southern Africa with the spread of the Bantu speakers from Shaba caused by better food-producing techniques. By providing a description of Bantu civilization, as if this civilization had not been altered much before $1500 \mathrm{~A} . \mathrm{D}$., he at tempted to fit the paradigm into the mold of Braudel's longue durée. Randles re-introduced in this fashion the old notion of a civilization that spread with language to all parts of Bantu speaking Africa and reinforced old notions of an unchanging "traditional society." 206

The Search for a New Paradigm

1973 was a turning point for Bantu studies. It saw the publication of articles by Bernd Heine and Alex Henrici which led to the proposing of a completely new paradigm. ${ }^{207}$ Heine and Henrici confirmed Ehret's findings but with fresh data and in greater detail. The importance of Henrici's contribution lay in the fact that he had used Guthrie's own data yet, by using lexicostatistics, had come to a genetic classification of the Bantu languages that was totally different. He concluded that the process of differentiation of Bantu languages involved a few languages splitting off from the "core" at different times. Heine's results were similar. His contribution was 
especially important in his argumentation for the use of basic vocabulary as a tool and in his conclusions which, by giving genetic sub-divisions, offered a hypothesis of the directions of language spread. First he showed that no results could be achieved by using the comparative method. Guthrie's classification ultimately derives from his zones, which were empirical or referential classifications rather than genetic ones.

For Heine, the reason for the failure of Finck, Guthrie, and others lay in the very strong convergence phenomenon in the Bantu area. He pointed out that all characteristic features of a language except vocabulary can disappear as a result of intensive borrowing, citing as examples the study of pidgin languages and the case of Mbugu in east Africa. Mbugu's grammar is fully Bantu, though its vocabulary is Kushitic. And of the vocabulary only a basic "culturally neutral" core remains relatively impervious to borrowing. Hence, given a high incidence of convergence (borrowing), the safest approach to a genetic classification is the use of a basic vocabulary, so that the use of a modified lexicostatistical list is necessary. 208

Heine's analysis showed that there had been three successive centers of Bantu expansion. The oldest in Cameroun led to some languages expanding short distances north and south, while others expanded further east and are now in northeastern Zaire. The second dispersal occurred north of the lower Zaïre and produced seven groups encompassing what is usually labeled western Bantu. The last dispersal probably took place in Kasai and produced all the eastern Bantu languages. ${ }^{209}$ This last center is close to Guthrie's "cradle" of Bantu languages but, since Guthrie primarily used eastern Bantu languages, this result was only to be expected. It follows from Heine's data that proto-Bantu roots must now be reconsidered. For example, Guthrie's roots for cattle, chicken, and ironworking all apply only to eastern Bantu; "cattle," and perhaps the others as well, is a loan.210

In 1975 Coupe $z$ and his colleagues confirmed Heine's findings in general, even though their work was based on a different set of lexicostatistical data. While Coupez had a wider base in eastern Bantu, more secure data, and a more sophisticated statistical approach, he lacked data on the northwestern Bantu languages. As a result his work is especially useful for subdivisions within eastern Bantu. But his conclusion that the eastern Bantu spread from Greenberg's nuclear area by skirting rather than crossing the forest does not really follow from his data. ${ }^{11}$

Meanwhile Ehret adopted a different approach to the problem. In a long study devoted to eastern Bantu he used loanwords in attempting to determine the evolution of these languages, and claimed to have found Central Sudanic loanwords in most of them. Since soandshifts can be traced in these loanwords, it is possible to subdivide eastern Bantu into groups on the basis of "shared innovation." Ehret saw the history of eastern Bantu languages as follows. Arriving at the western side of Lake Tanganyika about 600-400 B.C., Lega-Guha and the lacustrine groups split off from the rest of eastern Bantu shortly before the beginning of the Christian era. The remainder then split into a Kenya/Tanzania group and a southern Bantu group which correlated with "dimple 
based" and "channeled ware" potteries. The southern group later broke into seven subdivisions. ${ }^{212}$ This conclusion does not tally at all with Coupez, who divided eastern Bantu in four groups: Nyanga, Shona, $\mathrm{Zulu}$, and the rest, with the residue subdividing into five smaller groups. ${ }^{213}$ The differences between Ehret and Coupez were far more striking than the resemblances, and neither corresponds very closely to Henrici's subdivisions.

Beyond the general agreement between the results of Heine, Henrici, and Coupez, there were also significant differences. Thus Coupez included the whole of Guthrie's zone $\mathrm{K}$ and probably $\mathrm{R}$ in his eastern Bantu, whereas Heine excluded them, and Coupez integrated Heine's Aruwimi into Guthrie's zone C. This means that Coupez did not recognize much of the evidence adduced by Heine for an early fast movement of Bantu speakers from the lower Sanaga to the East. Despite basic agreement, then, between Heine, Henrici, Ehret, and Coupez about the process of splitting, much of the detail will require further data and study, if indeed it is possible to reach a valid genetic classification of eastern Bantu languages at all. Heine and others attempted partly to achieve this in 1977 by slightly enlarging the number of their test languages. In this they did not take cognizance of Coupez's work but did cite Ehret. ${ }^{14}$ Their results were largely similar to the results of Heine's earlier study, but it is evident, given the discrepancies among the three main classifications of eastern Bantu, that all the new proposals have a tentative air about them and that further revisions are to be expected.

This impression was confirmed by the conference on Bantu expansion at Viviers in April, 1977. Most of the participants were European scholars and the conference did not come up with any new paradigm. Among the points that were most hotly debated was the basic question of what is to be defined as "Bantu" and what is not. Thus Guthrie's groups $A 40$ and $A 60$ in Cameroun were discarded from a definition of "strict Bantu."215 The net effect is to confine the cradle of Bantu even more closely to the SanagaMbam area. But this conflicts with the results of the enquiry by Patrick Bennett and Jan Sterk, whose Bantoid is divided into several nodes, so that in the end Guthrie's zones A, B, C, and part of $\mathrm{D}$, along with Ekoid and Mbam-Nkam (Cameroun), form a Cameroun-Congo group, while the rest of Guthrie's zones D and zones E, F, G, H, K, L, M, N, P, R, and S form a block opposed to Tiv, with Tiv forming an "Ungwa" group. Cameroun-Congo is a subdivision of Wok, which also includes Jarawan. Wok and Ungwa are the two branches of "Bin," which corresponds to the "wider Bantu" of earlier definitions. ${ }^{216}$ Here, too, the different proposals have a tentative air about them. Most linguists seem to agree on a "wider Bantu" which would include some so-called Bantoid languages, but its subdivisions are far from evident at this time. Part or all of the northwestern Bantu languages may now be opposed to all others, even if the nature and the degree of opposition still remains unclear.

Meanwhile, Henrici's article had an impact on scholars at SOAS. David Dalby's rearguard action in defense of Guthrie's work was unconvincing. Dalby admitted that Guthrie had "cast his net too wide" and that some of the northwestern Bantu 
languages might have come directly from the Cameroun cradle. A second part of Dalby's article raised the occasional eyebrow when he once again used a geographical classification without any genetic significance as the basis for his discussion of protoBantu roots, without referring to the approaches of dialect geography. 217

Although shaken by Henrici's findings, Roland Oliver and Brian Fagan still adhered to Guthrie's hypothesis in their Africa in the Iron Age, but granted that "some" northwestern Bantu speakers settled on the way from the north to the nucleus south of the forest. Their map showed Bantu expansion flowing from Greenberg's cradle through the forest to cover all of it, before expanding later into eastern and southern Africa. In the text, though, they took pains to emphasize that in fact -- as Guthrie had postulated -- there had been a "rebound" from the nucleus into the forest to its north. To them this explained why the surviving areas of primary forest are all found in the northern portion of the equatorial rain forest. ${ }^{218}$ But the statement about the distribution of primary forest can also be disputed. Their scenario now had a stone age population of fishermen move from Cameroun to Guthrie's nucleus in Shaba, while the rebound consisted of farmers equipped with iron tools. Both iron and the Malaysian crops had reached the proto-Bantu in their Shaba home. So Greenberg's Bantu had no iron, but Guthrie's Bantu acquired it before they expanded.

Oliver and Fagan incorrectly based their view for this on Guthrie's own statements concerning proto-Bantu roots for iron and ironworking. 2 Ig Guthrie actually stated that ironworking was known in $\mathrm{PB}-\mathrm{X}$, that is, in the earliest stage of proto-Bantu. 220 In a separate article published in 1970 he asserted, despite the complications of the roots involved, that the proto-Bantu forged iron before their expansion, but that we cannot tell when they learned to sme it it. There may in fact have been a later, distinct introduction of ironworking to the East Coast. The migrating Bantu had elther forgotten their skill or acquired a new technique with novel terminology. 22 . This particular article was not cited by Oliver and Fagan, yet it was important, for it implied that the concept of Bantu speakers as originators of the dimple based/ channeled ware traditions was to be impaired. Oliver and Fagan continued to hold to the by-now traditional identification of these wares with Bantu expansion. 222

The question of whether proto-Bantu terminology included clear roots for ironworking or iron use was portentous. Pierre de Maret, an archeologist, and Yvon Nsuka, a linguist, collaborated in an attempt to solve it. They concluded that the facts were neither as clearcut nor as simple as Guthrie had presented them. On the whole they felt that the proto-Bantu did not know either how to smelt or to forge iron, concluding cautiously that "the case for Bantu metallurgy is far from being closed.223

In their latest study of linguistic and biological affinity among twelve Bantu-speaking populations, Hiernaux and Gauthier also notice Henrici's work, but not Heine's. They understood Guthrie to state that the expansion began after the Bantu became 
metallurgists, which would mean no earliex than c. 500 B.C., the date for ironworking in the Nok culture. The languages were carried by persons, so there was a possible biological correlation with the linguistic hypothesis. This they attempted to determine by using seven anthropometric variables. But the agreement between their results and those of Henrici was minimal. They argued that much of the divergence must be due to the influence of environmental factors which have blurred the genetic relationships. Therefore they thought that when a comparative study of blood types is possible, the fit with the linguistic hypothesis would become much better. 224

Oliver and Fagan returned to the issue once more. In doing so they accepted Henrici's framework and concluded first that the Bantu-speaking populations must have been confined for a period of several thousand years to the general northwestern region and perhaps to a small part of that region, while Bantu speech was carried into the remainder of the Bantu-speaking area in a later and much shorter period. 25 They associated the first spread with neolithic traditions, but still linked the spread of Bantu speakers in the savannas to the onset of the Iron Age. On the whole they now saw the ancestral language of the eastern Bantu dialects as a language spoken on the northern rim of the forest, where its speakers learned the elements of iron technology from a non-Bantu population living nearby. ${ }^{226}$ By about 500 B.C. Bantu peoples speaking languages ancestral to those of zones $C$ and $D$ were living astride the northern rim of the forest, while others in (and perhaps even south of) the forest had taken to a fisherman's iife and practiced vegeculture. North of the forest Bantu speakers raised cereal crops and kept stock. With the acquisition of metallurgy those groups spread and, because of their cereals, went around the forest rather than attempted to cross $i t$. In the end these eastern Bantu appeared on the southern margins of the forest, where they overlaid the earlier Bantu populations from the forest. By 1000 A.D. the expansion was at an end.227 In this schema the correlation between Bantu expansion and the spread of the Early Iron Age from northern Uganda to Natal was maintained. Nonetheless, the scenario had now become significantly different from the London paradigm of the 1960s. In a retrospective piece, Oliver stressed that, whereas in 1965 he was most influenced by linguistics, archeology had become the dominant influence a decade later. 228 He now unambiguously repudiated Guthrie's views for the first time. The London paradigm was dead; now the alleged close correlation between the archeological finds and the linguistic data was to be stressed. Older Bantu live in the forest and were neolithic; younger Bantu lived in the savanna and used iron. oliver called this correlation merely a "striking coincidence."229 As to the absorption of autochthones oliver now argued that this resulted from the more nucleated and more permanent settlements of farmers among hunters and gatherers, so that the latter abandoned their speech to adopt that of the centers. He now tentatively dated the northern Bantu astride the forest and in the savanna to c. 1000 B.C. Some later penetrated the forest, while others expanded toward the sources of the Ubangi river 
system. Iron still reached them from the north, but the invention of better iron and steel occurred in the interlacustrine area, as Peter Schmidt had recently shown. ${ }^{230}$ This is taken to explain the great expansionary potential of the interlacustrine area, from where all eastern and southern Africa was colonized. The division between eastern and western Bantu dialect clusters already existed when Bantu speakers occupied only the lands astride the northern rim of the forest; western Bantu came to be spoken in the forest, eastern Bantu in the savanna. In effect this article proposed a new paradigm, thereby reaffirming that a paradigm was possible in the present parlous state of our knowledge.

Meanwhile, archeologists had scarcely remained inactive. Some South African archeologists such as Derricourt and Inskeep had by 1973 come to think that there was no compelling evidence at all to link the advent of iron in eastern and southern Africa with the expansion of the Bantu speakers.231 Others, such as Peter Schmidt, accepted Huffman's understanding of the Early Iron Age as the development of a series of co-traditions and Schmidt drew the lesson from this that "reductionist arguments founded on ceramic evidence are no longer suitable," that is, archeology should no longer be used as an argument concerning the direction of migrations. ${ }^{232}$ Schmidt also pointed out that Oliver had evolved an automatic pattern of explanation that would fit almost any situation by linking expansion to population explosion and linking that to the ipso facto creation of surpluses when new crops are introduced. ${ }^{233}$

But D.W. Phillipson was still striving for an explanatory synthesis. In 1975 he had been able to provide a secure dating for the Early Iron Age, now understood as a single industrial complex, though expressed in at least twelve variants. These fell into three groups. Urewe, in the interlacustrine area, was the oldest and from it proceeded an eastern stream and a western stream. Phillipson's dating killed the notion of a single ancestral pottery that might have led directly to the development of the twelve variants. Moreover he now sharply distinguished between Early Iron Age and Later Iron Age, with the latter beginning around 1000 A.D. 234

Phillipson followed this up with three publications, of which the most complete is The Later Prehistory of Eastern and Southerm Africa, a book in which three chapters are devoted to this question. 235 He accepted Heine's results on the linguistic side and proposed the following scenario. By 1000 B.C. the protoBantu in Cameroun possessed agriculture and goats. One branch of the Bantu speakers went east along the fringe of the forest. There they met mixed farmers and acquired cereal agriculture, cattle, sheep, and iron metallurgy. This happened between 1000 B.C. and 400 B.C. Meanwhile, other groups traversed the forest between 1000 B.C. and 200 B.C. These people used pottery and ground stone artifacts. In the next stage some Bantu speakers moved from the interlacustrine area using Urewe ware and circumvented the forest as far as the Lower Zaire, introducing metallurgy wherever they went. The fusion of this group with the neolithic Bantu already there produced a western stream of Bantu, 
which then expanded through Angola to Namibia. Meanwhile, other interlacustrine Bantu went to the Kenya coast (100-200 A.D.) while a little later a major stream left the great lakes area to go to Transvaal, losing their cattle on the way to tsetse infection. At the same time the Kenya coast Bantu speakers also moved south to eastern Transvaal. By 400-500 A.D. Bantu from the western stream had entered Shaba, where they met eastern stream folk. A subsequent increase in population in Shaba led to the rise of Later Iron Age cultures, which spread over eastern and southern Africa between 1000 A.D. and 1600 A.D., bringing eastern Bantu speech to the region.

Phillipson's interpretation, though more explicit than Oliver's with regard to eastern Bantu, is very close to Oliver's later views. Phillipson links a remnant of the Guthrie/Dalby theory (the "Shaba nucleus") to Heine's views and uses it to account for a Later Iron Age. The interlacustrine area is credited with its usual pivotal role and the theory has become much more complex when it deals with eastern Bantu languages. Very little archeological work has occurred in the western half of the subcontinent, but Phillipson's theory does not take this fact into account. Even so, this complex hypothesis still did not do justice to Phillipson's own views on archeology since, in Zambia alone, he saw at least two distinct streams for the Later Iron Age, yet assigned only one set of languages (eastern Bantu) to both of them. ${ }^{23}$

So far few archeologists have completely rejected Phillipson's scheme but some are expressing doubts about some of the details, claiming, for instance, that there is no single Later Iron Age beginning c. 1000 A.D. ${ }^{237}$ The dating of Urewe ware may be too early, while a single Urewe tradition does not exist. ${ }^{238}$

Nicholas David rejects Phillipson's and Oliver's view that the Bantu speakers went around the forest. Instead he argued that Bantu speakers first occupied the forest, following river valleys, and in this way arrived in the then-heavily forested interlacustrine area, where Urewe ware developed. The use of iron also spread from west Africa along the same routes, but later this innovation reached the interlacustrine area via the forest. But David accepted Phillipson's views about the spread of eastern Bantu from the interlacustrine area southward. ${ }^{39}$

\section{The Disenchanted}

By the mid-1970s a number of scholars who were not connected with SOAS began to express their disenchantment with all the existing paradigms. The earliest was Lwanga Lunyiigo, for whom Bantu-speaking Negroes appeared very early and who claimed that the supposed exodus from west Africa never took place, and that the exact spot of origin of the Bantu languages cannot be determined. It is to archeology, Lwanga Lunyiigo argues, rather than to linguistics, that we must turn. On the basis of divergences in the opinions of such linguists as Greenberg, Guthrie, and Ehret, he dismisses them all. Noting the results of Schmidt in Buhaya, he maintains that the smelting of iron was independently 
discovered in east Africa. For him the interlacustrine area was the center from which metallurgy and dimple-based pottery, as well as agriculture, spread to central and southern Africa. Lunyifgo adds that the sickle cell gene also originated in east Africa and spread from there. All these east African contributions had a greater impact on central and southern Africa than any possible west African influences transmitted through Zaire. 240 In this contribution we see that "Bantu" used in a cultural sense has led to the exclusion of linguistic data altogether, even though the only rationale for grouping all the peoples of the "Bantu area" together is that they speak Bantu lanugages. In that sense the article does not deal with a Bantu expansion at a11! Instead it argues for important cultural diffusions that may have taken place alongside or outside any "Bantu migration." Richard Gramsley, an archeologist, also denied any Bantu migration, at least in the neolithic or after. Influenced by archeologists from South Africa, Gramsley claimed that pottery, food production, and ironworking did not spread simultaneously into eastern and southern Africa and that in any case none of these features can be associated with the spread of Bantu languages. Bantu, he thought, was spoken for millennia in many of the same regions where the languages are prevalent today, and the peoples of these regions have remained in the lands they occupied before the advent of food production, ceramics, and metals. 241

Writing in 1977 another archeologist, Pierre de Maret, wondered if in fact proto-Bantu as reconstructed is not actually a false creation, a synchronic projection by linguists of diachronic processes. He concluded that research in different disciplines should be kept more separate than is now the case and that to continue to build grand theory on so few data is more akin to tinkering than to scientific research. 242

Some radical linguists are even claiming that proto-Bantu is a chimera. Wilhelm Möhlig joins the latest position of David Dalby in his rejection of the idea of family-like relationships among languages. Convergence among Bantu languages has been so strong that no family tree can ever be reconstructed. Those who have tried to do so have completely ignored sociolinguistic findings as well as the findings of general dialectology. In such a situation dialectological approaches are the only valid ones, while both neo-classical comparative linguistics and lexicostatistics are inappropriate and lead only to false results. Möhlig emphatically claims that the eastern Bantu languages did not originate from a single ancestral tongue but represent blends of different genetic strata. Although he calls his approach "stratification theory," Möhlig still sees all the ancestors of eastern Bantu spakers as immigrants from an area located between the northeastern fringes of the forest and the western shores of the great lakes. And, unlike Gramsley, he still finds some agreement between his findings and Phillipson's paradigm. ${ }^{243}$

The latest contribution by cultural anthropologists is that of Adam Kuper and Pierre van Leynseele. They see the main question as knowing whether there existed a Common Bantu culture 
at all. If so, they argue, cultural anthropology can help reconstruct Bantu expansion. If we do not now know whether there was a Common Bantu culture or not, lack of adequate methodology must be blamed. The study of cultural processes can help indicate how an eventual Bantu migration could or could not have proceeded. Thus, for instance, if the initial movement was due to fishing peoples, then our knowledge about the cultures of fishermen in and out of the forest today is a relevant analogy. 244

The Phillipson and oliver paradigms are not now in general favor. For the past several years great disarray has reigned, so much so that some authors have begun to deny the problem altogether: there was no proto-Bantu, there were no migrations. Others believe that some time in the future a paradigm can be found, but not before we have many new data and new techniques. Yet, so far there are no signs of a moratorium being called on speculation about Bantu origins, as there once was one about surmise concerning the origins of language. The temptation to find the solution is apparently still too great, but disenchantment is spreading, bringing in its wake a much more critical attitude toward the existing framework of speculation. Paradoxically, perhaps, the disenchanted do not reject speculation per se but use their imaginations more freely in speculating and in seeing the numerous possibilities that cannot be accommodated by the framework in which the Bantu question was cast more than a century ago. Perhaps Indo-European historical linguistics was never the proper analogy to use.

\section{EPILOG}

This survey of speculation about Bantu expansion inevitably leads to some further considerations. At the most specific level one may well ask: What has the result been? What do we know today and what progress has a century of speculation achieved? By its very formulation the question of Bantu expansion also raises problems about the relationship between linguistic, cultural, and social phenomena and thus problems about interdisciplinary research in general.

\section{The Status of "Bantu Expansion" Today}

Recent linguistic research has shown that proto-Bantu must be understood as a set of closely-related dialects or languages seen at a given, and rather arbitrary, moment in time, the moment being an effect of the choice of languages drawn into the comparison. Proto-Bantu also is a "moment of the mind" in that the reconstructions may not represent a single language actually spoken by living people, but rather may constitute comparative formulas which express shapes and meanings used within the numerous proto-Bantu dialects. We must assume, moreover, that linguistic differentiation at the time was already accompanied by processes of convergence, so that proto-Bantu cannot be said to reflect the speech of a single community but rather of a congeries of communities interacting with each other. It follows that a cultural 
uniformity cannot be postulated as a correlation of the language situation. Some communities may have been fishermen, others farmers. Some communities may have exhibited a certain social organization while others may have been organized quite differently. The proto-Bantu focus is not sharp; it refers to several languages and several communities. The moment of proto-Bantu falls between c. 1500 B.C. when cereal agriculture appears, and c. 500 B.C., when the knowledge of ironworking began to spread. The moment itself also must be considered as somewhat blurred, because of convergence phenomena. Proto-Bantu can refer only to a period of unknown duration, during which the congeries of Bantu languages differentiated from its neighbors. The localization of protoBantu in space also is not precise. The congeries of tongues and communities was settled between the Benue, the Cross, and the Sanaga rivers.

After the "moment" of proto-Bantu further linguistic differentiation occurred, though not necessarily at a rapid or constant rate, as Greenberg postulated. ${ }^{45} \mathrm{All}$ we can say today is that the Bantu congeries first expanded in the most northwesterly part of the forest and that further spread occurred broadly from northeast to southwest. Geography and topography no doubt played a significart. role, as is shown by the differences in the strength of convergence among savanna languages, where convergence is very strong, and parts of the forest, where convergence is much less evident -- although in other parts, such as within the Congo river bend or east of the Upper Zaire fairly strong evidence of convergence also appears. The mobility of individuals, more than the mobility of groups, also played a major role in the evolution of the Bantu languages as differentiators and as instruments for convergence.

Nor can the process of expansion necessarily be seen as occurring in ever-widening circles. All we know is that, by the eighth century A.D. at the latest, Bantu terms from the east coast were reported by Arabs. Perhaps the dialectological study of items relating to metallurgy, Malaysian crops, or fowl may be of some help in establishing relative stages of spreading, but even this is doubtful since convergence also acted on these items.

How were the languages carried? The main mechanism may have been drift, rather than migration, though migration cannot be excluded entirely. Other mechanisms probably were the development of linguae francae, used by traders and traveling artisans; the development of koine, new languages accepted over an area as "standard intercommunity speech" and related no doubt to the preferences of elites; the occurrence of language shifts as aboriginal populations abandoned their speech in favor of a Bantu language, perhaps because for hunters and gatherers leading a nomadic life, a Bantu-speaking farming village became a cultural center for a region. Any and all of the forces sociolinguists have discovered may have operated at different times in different places and with different intensities. It is not certain at all that any population explosion was ever needed to account for this spread, nor is the contrary -- the extinction of aboriginal 
populations -- a necessary implication of the Bantu language spread. Moreover, language did not necessarily spread with any of the more "advanced" arts such as agriculture and metallurgy, let alone with new pottery styles. Rather, new fashions, new objects, and new techniques could diffuse in all directions almost indiscriminately. The fact that the center of the Bantuspeaking area in Shaba shows such a very high impact of convergence shows that this area has been continuously open to diffusion. Faced with this type of situation, involving such a large area and such great time depth, along with such a lack of precise evidence, the historian wants to proceed from the known to the unknown, from the recent past to the more remote past. He would like to see linguists concentrate on the reconstruction of shallowlevel language groups within Bantu and on the study of linguistic items through space which may help to distinguish later layers of convergence and later differentiations from earlier ones. 246 He also wants now to keep linguistic and other (mainly archeological) data and argument separate. In archeology, as in language, the historian wants to see more work on later periods, and in this case specifically he wants more excavations in the western half of the Bantu-speaking area. What linguistics call strong convergence among the eastern Bantu languages, archeologists seem to call "co-tradition." The two phenomena may be two aspects of the same processes. So the historian wants to know more about different diffusions at different times, which means more sites excavated, with better dating and interpreted with less and less extrapolations as to time, space, and artefact associations. From other disciplines historians want information about social, cultural, and linguistic processes that would be acceptable analogies to the situations in Bantu Africa.

We have gone as far as we can with the present paradigms, which have not really stood up well. As a result, new beginnings on limited portions of the Bantu question are required, rather than new paradigms. Past speculation has led to modest progress, although perhaps most progress was not actually inspired directly by previous speculation. Thus Guthrie's historical conclusions were merely a by-product of his work rather than a direct result of earlier speculation. On the other hand the work of Heine, Henrici, and Coupez was directly related to earlier speculation. No site has yet been chosen to test a particular assumption from one of the paradigms, although present research in the southern Sudan may relate to this and although in general the paradigms have given enhanced respectability to archeologists specializing in the Early Iron Age.

By now a sufficiently large corpus of speculation exists that any new linguistic, cultural, agricultural, social, biological, or archeological research in the Bantu-speaking areas can find in the existing literature a frame of reference and, perhaps as importantly, arguments for its justification. In this regard speculation has been useful and the most useful speculation undoubtedly has been Murdock's. But insofar as past speculation has not led directly to testable hypotheses, it has remained barren. If any future paradigms should be offered, scholars would be entitled to ask for a complex, monographic treatment, 
accompanied by testable hypotheses. Complex because realistically such a language spread over such an area and over such a long time period can be accounted for only by a complex paradigm. Accompanied by testable hypotheses because any paradigm must primarily be judged by the real advance of knowledge that results from its existence. Speculation must stimulate research in order to justify itself.

\section{"Bantu Exponsion" and Interdiscip Iinary Research}

From the very beginning, it was clear that any proposed solution to the question of "Bantu expansion" required interdisciplinary efforts. Of the main paradigms only Johnston's was the work of one person, admittedly a polymath. The other paradigms associated a linguist with another specialist. Murdock relied on Greenberg, Oliver on Guthrie, and Phillipson on Heine. More recently the paradigms also included at least one archeologist. Oliver relied more and more on Fagan while Phillipson, himself an archeologist, has elaborated the latest full paradigm. And if we are to judge by the evolution of a similar situation in the study of Indo-European expansion, this evolution is normal. Only specialists in linguistics and archeology can bring really new data to the debate.

A special twist in the African situation has been the training of scholars in several disciplines. For instance, Johnston the polymath was followed by Ehret, an historian cum linguist; Schmidt, a historian cum archeologist; and Hiernaux, a biologist cum archeologist. Historians and anthropologists such as Oliver or Murdock have not really added much to the discussion, except by attempting to coordinate other views into a single grand whole. In the future this coordinating role may, given the time depth involved, devolve more and more on archeologists rather than historians. As to anthropologists, they may provide more analogies from which to reason, rather than "survivals," allegedly attesting to situations of millennia ago.

One may well ask what the effects of this interdisciplinary approach have been so far. First, it is obvious that the conclusions of specialists have ineluctably been contaminated by their knowledge of the results in neighboring disciplines. The clearest case is perhaps Hiernaux's article, which took the London paradigm for granted and simply made the biological evidence fit it. 247 Here was a scholar who had just completed the major work on the biology of African populations ignoring his own results about the impact of similar environments in order to attribute similarities among Bantu-speaking populations along the fringes of the forest to an unchanging genetic make-up rather than to the milieu. Hiernaux later redeemed himself in a systematic comparison that showed the lack of apparent correlation between the linguistic situation as found by Heine and the biological distrijutions. ${ }^{48}$ Similarly, Phillipson's use of Heine led him to overemphasize the flimsy archeological evidence for a single "Later Iron Age" in eastern and southern Africa. Indeed, the archeological appreciation of the pottery traditions involved 
in the Early Iron Age there was also strongly colored by the archeologists' knowledge of the linguistic status questionis. The lumpers lumped because it fitted linguistic evidence, and, while the splitters split because of archeological necessity, the "co-tradition" concept once again allowed correlation with the linguistic data. From this one could argue that interdisciplinary research tends to have deleterious effects on the interpretion of one's own research!

Another effect of interdisciplinary approaches snown by the Bantu data is that students of one discipline do not always understand quite what another discipline strives to do. In 1965 Oliver may not have understood what the archeological data about eastern and southern Africa really were. Archeologists knew that the then-current interpretations were ephemeral because the lacunae were still so massive that every interpretation made intolerable extrapolations with regard to space and time and could be overturned by the results of the very next site excavation. More recently, Phillipson's arrangement of twelve ceramic traditions into two Early Iron Age streams and his distinction of two Late Iron Age traditions in Zambia can be fully grasped only by other archeologists; only they know that the situation is not quite that clear yet and that this tidy view hides an unduly adventurous interpretation of the available data. They may well feel, for instance, that Kapwirimbwe and Chondwe should not be separated; that Urewe is a lumped category, not a single tradition; and that establishing a simple Lwangwa tradition, and even more a single Lungwebungu tradition, is an unsubstantiated leap of faith. Only archeologists know too how tenuous the connection between cultural change in general and changes in pottery traditions can be.

Similar comments can be made about the other disciplines. How many historians could even see that Guthrie's calculations of Common Bantu roots involved a notion of archaism which they would never accept in their own discipline? How many saw the obvious flaw in Murdock's thesis: his derivation of proto-Bantu society and culture on the basis of "survivals," a notion that few historians would accept? Lunyiigo's stance is a good illustration of what can go wrong when data from other disciplines are used injudiciously. Because of the lack of consensus among linguists (e.g., Greenberg and Guthrie) he simply rejects all linguistic evidence out of hand. He rightly suspects archeologists who seem to use only those $C^{14}$ dates which "fit" and reject the others. He is confident of sickje cell data but does not realize how this hereditary trait is linked to environmental conditions. In the end he is hoist by his own petard.

Even the scholar who was trained in another discipline has difficulties because the disciplines evolve over time, each in their own different ways. Since Johnston's time physical anthropology has undergone a major transformation. In linguistics the approaches changed with the arguments of Greenberg, again with Heine, and more recently yet again with Möhlig. Even Meinhof and Guthrie do not stand on exactly the same theoretical ground. For Meinhof Ur-Bantu was once a real language, from 
which conclusions can be derived, while for Guthrie common Bantu starred forms were merely convenient comparative formulae from which very few conclusions could (or should) be derived. In archeology technical advances have played a major role. In terms of dating techniques we can discern three epochs: pre- $\mathrm{C}^{14}$, the post-C $\mathrm{C}^{14}$ euphoria, and, since the late 1960s, the age of second thoughts. There is an age of pre-flotation techniques and an age with flotation techniques and this has had a marked impact on the data available concerning evidence for domestic plants, and so on. No wonder that Ranger could observe that

"it would be a rash historian who today accepted the conclusions of Garlake and Huffman with the same simple-minded trust as I myself accepted the conclusions of Summers and Robinson."249

Ranger's disillusionment aptly illustrates the problems in understanding data from other disciplines. Clearly the expedient usually used in accepting such data, namely the degree of consensus at a given moment in that discipline, is simply invalid.

In theory at least, independent confirmation of a situation by data from different disciplines strengthens any argument. But first we must be certain that they address the same evidence. Thus a correlation between Early Iron Age and Bantu expansion involves the premise that pottery and language travel hand in hand. A correlation between linguistic and biological evidence presumes migration as the mechanism of language spread; a correlation between architecture and linguistic distributions ties the two together. It has become painfully evident from the record that in most cases the evidence is not the same, so there is no independent confirmation of the data. To complicate matters the weight of proof for data from different backgrounds is not equal. How much could one really count on Johnston's fowl? The evidence is onomatopoeic and only linguists would likely be aware of how exiguous the particular argument was, for some ideophones are more convincing than others. ${ }^{250}$ The value of a given $\mathrm{C}^{14}$ date depends among other things on the association, on a set of dates, on the laboratory that processed them, on the method used, and on the substance from which it was derived. Archeologists are usually aware of this, which colors their attitudes toward such dates.

The most insidious difficulty with interdisciplinary research stems from the inevitable selectiveness in choosing data. The lacunae in all fields are still enormous. What seems today to be a strong correlation may be swept away when more data are uncovered. The scholar today inevitably builds his case from very few basic data and adds to it that which fits, ignoring other materials. This has occurred in all the major speculations. Johnston had an idea about what a Bantu language should be like and it governed his positioning of archaic languages, and the same is true of Guthrie. Johnston then fitted other evidence in. Thus the interlacustrine area was a secondary cradle because of the "antiquity" of the languages, allowing Egyptian influences to be postulated as coming up the Nile. Murdock needed the 
Malaysian plants to trigger the overpopulation and a Bantu dispersal and so he postulated the diffusion of these crops from the east African coast to Cameroun, necessary because he used Greenberg's hypothesis. Guthrie and Oliver had to postulate a mad dash across the rain forest to reconcile otherwise irreconcilable linguistic positions and oliver used a few $\mathrm{C}^{14}$ dates to invert the progression of the eastern and southern African Early Iron Ages. Phillipson accepted Heine and then ignored a major feature in Heine's hypothesis, the position of the third nucleus and its immediate ancestor, because that failed to fit with the archeological data he used.

The moral of the whole search for the Bantu in the crystal ball is clearly that if every specialist stays within his own discipline and does not worry unduly about the effects his findings might have on the question of Bantu expansion less distortion will result. True, there will be much less of a consensus, but at least inevitable contradictions will not be glossed over, so that the undeniable complexities of the issues relating to "Bantu expansion" will appear. The greatest defect of all hypotheses to date has been their reductionism. In their desire to present a single comprehensive explanation for a set of complex phenomena, all the scholars involved have succumbed to the temptation to oversimplify. The strongest reductionism occurred in equating language, society, and culture, sometimes even including physical population.

For the basic question about Bantu expansion involves the relationship between language, culture, society, and physical population. If all agreed that languages spread independently of culture, Bantu expansion would be no more of a problem than, say, the spread of throwing knives and clubs from Egypt to Zaire. The problem is important because researchers accept that there are some vital links involved. How then does one extrapolate from language to culture and society? For those such as the culture historians before World War II who did not believe in a strong association between language and culture, there is no Bantu question at a11, but others have accepted that the association is strong.

Murdock especially is clear on this. If two people speak related languages they are both descended from a single ancestral society or else one group abandoned their own language in favor of that of the other, which requires intimate and protracted contact. ${ }^{251}$ Murdock does not state, however, that the second group also took over the culture of the first group, and for good reason. We know for instance that the pygimes took over the languages, but not the cultures, of their neighbors. Again, Bira is spoken by farmers in the savanna, by farmers in the forest with a different social system and a different culture, and by pygmy hunters and gatherers in the forest. But when Murdock began his discussion of Bantu expansion he compared it with that of the Arabs and the Europeans, thus implying population movements as we11. 252 In the same way Johnston's conquest later became Oliver's colonization. Meinhof first believed in mass migration, but later saw the invaders as a superior minority. 
Phillipson, while not explicit, tracks migrations and links language, iron technology, and people. But this premise, which underlies the whole interdisciplinary effort, is very far from being proven.

Languages are spoken by people in a community, suggesting that when language spreads, there is a reasonable chance that this results from the spread of the speakers themselves. Greenberg argued this for Bantu and no one ever doubted him. Linguists have accepted this equation everywhere, for instance for the Austronesian or Indo-European expansions. 253 Nonetheless, it should be apparent that such an argument is far from necessarily true. Obviously, languages can spread without either a migration or the transfer of a whole social structure or culture. The only real requirement is that there should be a fairly intensive contact between different peoples, such as the contact which brought English to Japan or China.

Neighboring communities can take over the language of their neighbors because of the latter's perceived cultural superiority. Thus pygmies, who despise Bantu people, still borrowed their languages, presumably because of the centrality of Bantu settlements. Or whole communities can become bilingual as did a community sandwiched between the Central Sudanic-speaking Mangbetu and the Bantu-speaking Ababua. ${ }^{25}$ Once bilingual, a society may then develop a pidgin, which may in time become their mother tongue, as happened among the Mbugu of Tanzania or along the Marathi-Kannada boundary in India. ${ }^{255}$ On the other hand it may happen that no pidgin develops, but one language drives out the other, as recently happened among the Assax of Tanzania.256 or such language shifts may occur only among certain social classes in the society, as occurred on the French Flemish boundary in the eighteenth and nineteenth centuries.

The last case is an example of developments with a lingua franca. Such a language is used for inter-ethnic communication and can be adopted by one or another stratum of the societies involved. French was the diplomatic lingua franca of eighteenthcentury Europe and deeply penetrated upper middle class homes all over Europe. In a further step the lingua franca ous ts the original tongue and replaces it. In the process the lingua franca develops a dialect of its own in this population. This happened all over Roman Europe and to Mandarin in southern China. Here movement of people from the original community is involved, though on a small scale over a fairly long period of time. The evidence available certainly does not preclude the possibility that Bantu speech expanded in much the same way.

On balance, however, all these various possibilities (and others) do not seem at first likely explanations for the expansion of Bantu. After all, the geographical area involved is so massive that it is simplest to postulate a migration of some kind. Nevertheless, the more we learn from socio-linguistics, the more the presumption of migration will have to be re-examined. It is quite likely that in parts of the Bantu area the languages spread without population movement or without much of the culture or the social features of the original speech communty. 
The very fact that convergence is such a massive phenomenon among Bantu languages and occurs in phonology, morphology, and syntax, as well as in vocabulary, attests to the vitality of processes of diffusion other than migration. Once again the size of the area involved and the size of the time depth involved preclude any simple explanation. No "simple" migration can ever explain the spread of the Bantu languages, so the assumption that language $=$ culture $=$ community is a premise needing constant reassessment and refinement. And this is true regarding the relevance of interdisciplinary research. The techniques used by comparative linguists have necessarily led to the reconstruction of language differentiation as a genealogical tree. But this, too, is a premise. Non-linguists would do well to be cautious in accepting genealogical trees as revealed truth. ${ }^{257}$ Given the convergence phenomenon, the tree models are more than likely a false representation of affairs. And out with them goes, once again, the need for postulating migrations.

One can discuss premises made in relation to the Bantu languages, such as the speed or the constancy of the expansion, or the relationships between the shape of a term and its meaning over time, but it would serve only to emphasize the basic point that there is no law about the relationship between language, culture, and society. There is no overwhelming evidence for constant massive migrations carrying new cultures and new forms of society along with new languages to new areas. Evidently the relationship between language, culture, and society change at different times in different parts of the Bantu-speaking area, and within language itself there was a constant tug-of-war between differentiating and converging tendencies. Any premise which is based solely on constant relationships between language, culture, and society therefore is wrong, and any general rules about the relevance of this or that discipline to the question of Bantu expansion are misplaced. The inescapable conclusion is that Johnston posed and attempted to solve a false problem in 1886, when -- following the example of Indo-European scholars -- he attempted to account for the Bantu expansion. The problem is one of language only. Problems about the diffusion of crops, iron, musical instruments (xylophone), social customs (matrilinearity), domestic animals (fowl), or decoration and shapes in pottery all must be dealt with on their own merits. They al1 represent different and discrete phenomena. In fine this is the best reason why researchers of each discipline should concentrate on their own data in formulating their own conclusions. The chances that the diffusion of, say, pottery decoration is related closely to the diffusion of Bantu languages are infinitesimally small.

The very concept of a "Bantu expansion" carries by now too many axioms within itself. It is too misleading to be maintained as a goal for research. Much work remains to be done by linguists about both the synchronic and the diachronic problems of Bantu languages. Archeologists have barely begun to probe the sites they can uncover, especially in the western half of the Bantuspeaking world, while anthropologists should begin to examine dynamic processes in areas with related cultures, and biologists 
are only reaily beginning with the study of physical populations in relation to their environment and their past. It may be as much as a century too soon to reconstruct the last 3000 years or more of history in the Bantu-speaking subcontinent. It is not too soon, however, for historians (as opposed to archeologists and linguists) to become genuinely involved with recent linguistic history and with the Later Iron Age. There they stand a chance to join the results of different disciplines together into a coherent vision of the last half millennium. There they can learn what the pitfalls of evidence from all these disciplines are and what they can contribute to an overall reconstruction of the past.

\section{NOTES}

* The first part of this paper appeared in $H * 1,6(1979), 287-333$.

154. See Jan Vansina, "Bantu in the Crystal Bal1, I," History in Africa, 6(1979), 321-25. The social organization of Bantuists influenced the success of particular speculations, since such success is measured by the consensus of scholars, in turn strongly influenced by institutional realities.

155. Paul Schebesta, Die Bambuti-pygmäen vom Ituri, (Brussels, 1950); V. van Bulck, "Het probleem der Pygmeeëntaal volgens Schebesta," Kongo-Overzee, 14(1948), 305-09.

156. G.P. Murdock, Africa: Its Peoples and their Culture History (New York, 1959), 12 .

157. Ibid., 45 .

158. Ibid., 271-74.

159. Ibid., 279.

160. Ibid., 279, 300 .

161. Ibid., 349-50.

162. Ibid., 306, 357, 373.

163. Ibid., 377.

164. Ibid., 383-86.

165. Ibid., 96-99, 277.

166. D. Clark, "A Note of the Pre-Bantu Inhabitants of Northern Rhodesia," South African Joumal of Science, 47(1950), 80-85; R. Oliver and B. Fagan, Africa in the Iron Age: C. 500 B.C. to A.D. 1400 (London, 1975), 94-96.

167. Clark, The Prehistory of Southern Africa (Harmondsworth, 1959), 21-22, 283.

168. Ibid., 283.

169. Ibid., 283-84.

170. Ibid., 303.

171. Ibid., 311-12.

172. J. Hiernaux, Le début de $I^{\prime}$ age des métaux dans la région des grands lacs" in G. Mortelmans and J. Nenquin, Actes du Ivo Congrès panafricain de préhistoire et de l'étude du quatemaire (Tervuren, 1962), 382; M. Posnansky, "Bantu Genesis," Uganda Joumal, 25(1961), 86-93. Compare this with his slightly earlier "Pottery Types in East Africa," $J A H, 2(1961), 183-85$.

173. Posnansky, "Bantu Genesis," 91-92. 
174. (London, 1959), 130-31.

175. Wrigley, "Speculations on the Economic Prehistory of Africa," $J A H, 1(1960), 196$. The text dates from November 1958 and was presented to the African History Seminar at SOAS. Minutes $\mathrm{AH} / 58 / 4$.

176. Ibid., 202, and interventions in the SOAS seminar on 14 January and 18 February, 1959.

177. Ibid., 198, and SOAS seminar session 14 January 1959 for his source, Malcolm Guthrie.

178. SOAS seminar session.

179. Session of 28 January 1959, amplified in the sessions of 4 February, 11 February, 18 February, and 4 March.

180. Proto-Bantu had a term for iron, said Guthrie at the seminar on 28 January. Oliver's formulation of what became the London paradigm first occurred on 18 February 1959 at the seminar.

181. Concluding statement of the session of 4 March.

182. G.W.B. Huntingford, "The Peopling of the Interior of East Africa by its Modern Inhabitants" in R. Oliver and G. Mathew, History of East Africa, I (London, 1963), 58-93, esp. 81-92.

183. (Harmondsworth, 1962), 29-32. There are some shifts in Oliver's position in later editions of this very influential textbook.

184. Guthrie, "Some Developments in the Prehistory of the Bantu Languages," JAH, 3(1962), 273-82; idem, "Bantu Origins:

A Tentative New Hypothesis," Joumal of African Languages, 1(1962), 9-21; idem, "A Two-Stage Method of Comparative Bantu Study," African Language Studies, 3(1962), 1-24. Compare with his earlier "Problèmes de génétique linguistique: la question du Bantou commun," Travaux de l'Institut de Linguistique de l'Université de Paris, 4(1959), 83-92.

185. Guthrie, "Some Developments," 276.

186. Idem, "Bantu Origins," 16.

187. Hem, "Some Developments," 279-82.

188. H. Deschamps, I'Afrique noire précoloniale, (Paris, 1962), 29-31. As a Que sais-je? volume its impact in the Francophone world was great.

189. Cornevin, Histoire de L'Afrique, I, Des Origines au XVI Siècle, (Paris, 1966), 377-78. Compare with his Histoire des peuples de l'Afrique noire, (Paris, 1960), 151-52, where he accepted Greenberg but saw the Bantu expansion as circumventing the forest, rather like Johnston or like some recent speculations. By 1966 the cause of Bantu expansion was seen to be the desiccation of the Sahara, a point taken from Clark, "The Prehistoric Origins of African Culture," JAH, 5(1964), 181-82.

190. For instance see R. Rotberg, A Political History of Tropical Africa (London, 1965), 5n2 and 52n66. The information there may date from 1962.

191. R. Oliver, "The Problem of Bantu expansion," JAH, 7(1966), 361-76, first delivered as a lecture in 1965 at the Royal Society of Arts in London. Cf. R. Oliver, "Cameroun -- 
The Bantu Cradleland," Sprache und Geschichte in Afrika, $1(1979), 7$.

193. M. Posnansky, "Bantu Genesis: Archaeological Reflexions," $J A H, 9(1968), 1-11$. See also his "The Iron Age in East Africa" in W.W. Bishop and D.J. Clark, eds, Background to Evolution in Africa (Chicago, 1967), 629-49, and J. Hiernaux, La Diversité Humaine en Afrique Subsaharienne (Brusse1s, 1968). See Hiernaux, The People of Africa (New York, 1974), 175-89.

194. J. Hiernaux, "Bantu Expansion: The Evidence from Physical Anthropology Confronted with Linguistics and Archaeological Evidence, JAH, 9(1968), 505-15.

195. Neither had up to then published a formal rebuttal. Meeussen was waiting for Guthrie's magnum opus to be completed and so probably was Greenberg. But meanwhile both had expressed their misgivings and objections orally.

196. B.M. Fagan and R. Oliver, "Wenner-Gren Research Conference on Bantu Origins in Sub-Saharan Africa (Summary Report and Recommendations)," African Zanguage Review, 7(1968), 140-46; T. Grundemann, "Wenner-Gren Conference on Bantu Origins," Bulzetin of the African Studies Association of the United Kingdom (1968), 1-9. Other information from my own conference notes.

197. T. Huffman, "The Early Iron Age and the Spread of the Bantu," South African Archaeological Bulletin, 25(1970), 3-21.

198. J.D. Clark, The Prehistory of Africa (London, 1970), 210-14; Idem, "African Prehistory" in D. Dalby, Language and History in Africa (London, 1970), 1-19 esp. 9-15. This volume contains papers presented at the African History Seminar of SOAS from 1967 to 1969. On Bantu expansion it also contains M. Guthrie's "Contributions from Comparative Bantu Studies to the Prehistory of Africa," 20-49, and W.M. Mann's "Internal Relationships of the Bantu Languages: Prospects for Topological Research," 133-45, which prefigures A. Henrici's later and revolutionary findings.

199. J. Vansina, "Inner Africa," in A.M. Josephy, ed., The Horizon History of Africa (New York, 1971), 261-66.

200. Ibid., 265.

201. C. Ehret, "Cattle-Keeping and Milking in Eastern and Southern African History: The Linguistic Evidence," JAH, 8(1967), 1-17.

202. Idem, "Bantu Origins and History: Critique and Interpretation," Tronsafrican Jourmal of History, 2(1972), 1-10.

203. J. Greenberg, "Linguistic Evidence Regarding Bantu Origins," $J A H, 13(1972), 189-216$.

204. (New York, 1968), 57-114; H. Gailey, History of Africa from Earliest Times to 1800 (New York, 1970), 29-31.

205. (Paris, 1970), 355-63.

206. W.G.L. Randles, "La civilisation bantou: son essor et son déclin," Annales: Economies, Sociétés, Civilisations $29(1974), 267-81$.

207. B. Heine, "Zur genetische Gliederung der Bantu-sprachen," 
Afmika-Ubersee, 56(1973) 164-85; A. Henrici, "Numerical Classification of Bantu Languages," African Language Studies, 14(1973), 82-104.

208. B. Heine, "Gliederung," 164-70.

209. Ibid., 172-75.

210. Ibid., 181-82.

211. A. Coupez, E. Evrard, and J. Vansina, "Classification d'un échantillon de langues bantoues d'après la lexicostatistique, Africana Linguistica, 6(1975), 133-58. Data for the project had been assembled from 1954 onwards. The conclusions about migrations are exclusively Coupez's.

212. Ehret, "Patterns of Bantu and Central Sudanic Settlement in Central and Southern Africa, Transafrican Jourmal of History, 3(1973), 1-71.

213. A. Coupez, "Classification," 152 .

214. B . Heine, H. Hoff, and R. Vossen, "Neuere Ergebnisse zur Territorialgeschichte der Bantu," in W.J. Möhlig, F. Rottland, and B. Heine, Zur Sprachgeschichte und Ethnohistorie in Afrika (Berlin, 1977), 57-70.

215. The main publication of this conference will be $\mathrm{C}$. Bouquiaux, G. Manessy, and J. Voorhoeve, $L^{\prime}$ expansion bantoue. I have seen most of the linguistic papers, while some others, such as the anthropologists $A$. Kuper and P. Van Leynseele, or archeologists such as N. David, P. de Maret, and F. Van Noten kindly sent me copies of their papers, for which I am very grateful. Information about $A 40$ and $A 60$ from Dr. J. Voorhoeve, confirmed by others.

216. P. Bennett, and J. Sterk, "South Central Niger Congo: A Reclassification," Studies in African Linguistics, 8(1977), 241-73.

217. D. Dalby, "The Prehistorical Implications of Guthrie's Comparative Bantu," JAH, 16(1975) 481-502; 17(1976), 1-28. Since then Dalby has abandoned the idea of genetic relationships between languages altogether. See his Language Map of Africa and the Adjacent Islands (London, 1977).

218. Oliver and Fagan, Africa in the Iron Age, 78-79.

219. Ibid., 32 .

220. Guthrie, Comparative Bantu (4 vols.: Farnborough, 1967-71) 1: no. $74 / 21,74 / 25 ; 2: 83 / 24$.

221. Guthrie, "Contributions from Comparative Bantu Studies to the Prehistory of Africa" in Dalby, Language and History, 28-30, 44-45.

222. Oliver and Fagan, Africa in the Iron Age, 73-75.

223. P. de Maret and Y. Nsuka, "History of Bantu Metallurgy: Some Linguistic Aspects," History in Afyico, 4(1977) 43-66.

224. J. Hiernaux and A.M. Gauthier, "Comparaison des affinités linguistiques et biologiques de douze populations de langue bantu," Cahiers d'études africaines, 66/67(1977), 241-53.

225. R. Oliver and B. Fagan, "The Emergence of Bantu Africa" in The Cambriage History of Africa, II, From C.500 B.C. to A.D. 1050, (Cambridge, 1978), 342-409, 750-56.

226. Ibid., 357-59, 405-06. 
227. Ibid., 358.

228. Oliver, "Cameroun," 7.

229. Ibid., 10 .

230. Ibid., 17. Metallurgy, he now surmises, derived from the Upper Uele. His argument is partly based on resemblances between newly-discovered pottery from that area and Early Iron Age pottery of Urewe ware as in R.C. Soper, "Resemblances Between East African Early Iron Age Pottery and Recent Vessels from the North-Eastern Congo," Azania, 6(1971) 233-41.

231. R.M. Derricourt, "Classification and Culture Change in Late Post-Pleistocene South Africa" in C. Renfrew, ed., The Explanation of Culture Change: Models in Prehistory (New York, 1973), 625-31.

232. P. Schmidt, "A New Look at Interpretations of the Early Iron Age in East Africa," History in Africa, 2(1975), 127-36.

233. Ibid., 133-35.

234. D.W. Phillipson, "The Chronology of the Iron Age in Bantu Africa," JAH, 16(1975), 321-42.

235. Idem, (London, 1977), 102-230. Summary of his ten stages of Bantu expansion, 227-30. See also idem, "Archaeology and Bantu Linguistics," World Archaeology, 8(1976), 65-82; idem, "The Spread of the Bantu Language," Scientific American, 236(1977), 106-14. Cf. also his "The Early Iron Age in Eastern and Southern Africa: A Critical Reappraisal," Azania, 11(1976), 1-24.

236. Idem, Later Prehistory, 172-79.

237. See, for instance, P. de Maret, F. Van Noten, and D. Cahen, "Radiocarbon Dates from West Central Africa: A Synthesis," $J A H, 18(1977)$, 497-501.

238. F. Van Noten, "The Early Iron Age in the Interlacustrine Region. The Diffusion of Iron Technology," paper presented at the Viviers Conference.

239. N. David, "The Archaeological Background of Cameroonian History," paper presented at the Viviers Conference.

240. Lwanga Lunyiigo, "The Bantu Problem Reconsidered," Current Anthropology, 17(1976), 282-86.

241. R. Gramsley, "Expansion of Bantu-speakers versus Development of Bantu Language and African Culture in situ: An Archaeologist's Perspective," South African Archaeological Bulletin. 33(1978), 107-12.

242. P. de Maret, "Bribes, débris et bricolage," paper presented at the Viviers Conference.

243. W. Möhlig, "The Bantu Nucleus: Its Conditional Nature and Its Prehistorical Significance," Sprache und Geschichte in Afrika, 1(1979), 109-42. Earlier articles by Möhlig in the same vein are "Guthries Beitrag zur Bantuistik aus heutiger Sicht," Anthropos, 71(1976), 673-715; "Zur frühen Siedlungsgeschichte der Savannen-Bantu aus authistorischer Sicht" in Möhlig, Rottland, and Heine, Sprachgeschichte, 166-93. His "The Problem of a True Historical Classification of the Bantu Languages," submitted to the African Linguistics 
Colloquium of Leiden in 1978 is expected in due course.

244. A Kuper and P. Van Leynseele, "Social Anthropology and the 'Bantu Expansion'," Africa, 48(1978), 335-52.

245. J. Greenberg, The Languages of Africa (B1oomington, 1963), 38 , calls it a "relatively recent movement" on the basis of the wide extension of Bantu languages and the relatively small differentiation among them. But strong conversion also exists among many Australian languages, which must have been spread over the whole of Australia millennia ago. See R.M.W. Dixon, "The Nature and Development of Australian Languages," Annual Review of Anthropology, $8(1979), 433$. The rate of differentiation is not necessarily constant as, e.g., the development of English shows. On this point Johnston may be right; see the first part of this article, 312 .

246. Möhlig, "Bantu Nucleus," 123-26, 131-33.

247. Hiernaux, "Bantu Expansion."

248. Hiernaux and Gauthier, "Comparaison."

249. T. Ranger, "Towards a Usable African Past" in C. Fyfe, ed., African Studies Since 1945 (London, 1976), 21.

250. L. Casson, "Who First Crossed the Oceans?" in L. Casson, Mystemies of the Past (New York, 1977), 30, mentions the same onomatopoeia: (kuk) as Polynesian and Peruvian terms for "chicken." On the other hand some onomatopoeia, such as those used for "be11" in Africa, are so numerous and variable that such terms may have value as proof because so very many possibilities exist. On fow1 consider also the English cock, French coq, both very close to kuk!

251. Murdock, Africa, 2 .

252. Ibid., 271.

253. R. Anttila, An Introduction to Historical and Comparative Linguistics (New York, 1972), 386-87.

254. For the Mambese see F. de Maeyer, "Een elgenaardig geval van tweetaligheid op de taalgrens der Soeden- en Bantoetalen in Belgisch Kongo," Kongo-Overzee, 9(1943), 173-75.

255. Anttila, Introduction, 173-74.

256. J.C. Winter, "Language Shift Among the Aasax, a HunterGatherer Tribe in Tanzania," Sprache und Geschichte in Afrika, 1(1979), 175-204.

257. Dalby, "Prehistoric Implications," 487-89, 501. 